Western University

Scholarship@Western

$10-2006$

\title{
Environmental Equity Is Child's Play: Mapping Public Provision of Recreation Opportunities in Urban Neighbourhoods
}

Jason Gilliland

The University of Western Ontario

Martin Holmes

The University of Western Ontario

Jennifer D. Irwin

The University of Western Ontario

Patricia Tucker

The University of Western Ontario

Follow this and additional works at: https://ir.lib.uwo.ca/geographypub

Part of the Geography Commons, and the Public Health Commons

Citation of this paper:

Jason Gilliland, Martin Holmes, Jennifer D. Irwin \& Patricia Tucker (2006) Environmental equity is child's play: mapping public provision of recreation opportunities in urban neighbourhoods, Vulnerable Children and Youth Studies, 1:3, 256-268, DOI: 10.1080/17450120600914522 


\section{Environmental equity is child's play: mapping public provision of recreation opportunities in urban neighbourhoods}

Jason Gilliland, Martin Holmes , Jennifer D. Irwin \& Patricia Tucker

To cite this article: Jason Gilliland, Martin Holmes, Jennifer D. Irwin \& Patricia Tucker (2006) Environmental equity is child's play: mapping public provision of recreation opportunities in urban neighbourhoods, Vulnerable Children and Youth Studies, 1:3, 256-268, DOI: 10.1080/17450120600914522

To link to this article: https://doi.org/10.1080/17450120600914522

Published online: 30 Nov 2006.

Submit your article to this journal $\pi$

Џ Article views: 383

Q

View related articles $\sqsubset$

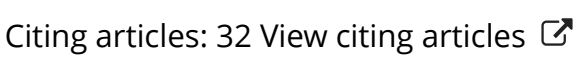




\title{
Environmental equity is child's play: mapping public provision of recreation opportunities in urban neighbourhoods
}

\author{
JASON GILLILAND ${ }^{1}$, MARTIN HOLMES ${ }^{1}$, JENNIFER D. IRWIN $^{2}, \&$ \\ PATRICIA TUCKER ${ }^{2}$
}

\author{
${ }^{1}$ Department of Geography, and ${ }^{2}$ Faculty of Health Sciences, The University of Western Ontario, \\ London, Ontario, Canada
}

\begin{abstract}
This paper examines the spatial distribution of recreational opportunities for children and youth in a mid-sized Canadian city (London, Ontario), in relation to the socioeconomic status of neighbourhoods and estimated local need for publicly provided recreation spaces. Public recreation facilities $(N=537)$ throughout the city were identified, mapped and analysed in a geographic information system. To explore potential socio-environmental inequities, neighbourhoods $(N=22)$ were characterized by socioeconomic and environmental variables, an index of neighbourhood social distress, a neighbourhood play space needs index, and measures of the prevalence and density of recreational opportunities. The results of the spatial analysis indicate there is no systematic socioenvironmental inequity with respect to the prevalence and density of publicly provided neighbourhood recreation spaces; however, there are several areas in the city where youth do not have access to formal play spaces. We argue that to promote physical activity among urban children and youth, city planners and health policy analysts should consider carefully the geographical distribution of existing recreational opportunities and ensure that new publicly funded recreation spaces are provided to neighbourhoods with the greatest need. Further research should seek to identify what kinds of recreation spaces are most effective for promoting healthy behaviours among vulnerable children and youth.
\end{abstract}

Keywords: Children, geographic information systems, neighbourhood, physical activity, recreation, socioeconomic status, youth

\section{Introduction}

Childhood obesity is a burgeoning public health problem in many developed countries. Between one-quarter and one-third of children in Canada, the United Kingdom and the United States are overweight or obese (American Obesity Association, 2002; National Statistics, 2004; Tremblay \& Willms, 2000; Tremblay et al., 2002). While health researchers have focused traditionally on the individual level factors (e.g. genetics) associated with obesity, recent work has suggested that local environments may also influence body weights and overall well-being through the opportunities they provide for promoting or hindering healthy behaviours, such as physical activity (Frank et al., 2005; Macintyre et al., 2002; 
Saelens et al., 2003). For young people in particular, easy access to opportunities for recreation is an important determinant of physical activity - a modifiable behaviour - as they have greater transportation challenges than adults. Previous research has shown that children from socially disadvantaged environments (households and neighbourhoods) are more vulnerable to obesity and obesity-related health problems (Lin et al., 2004; Storey et al., 2003; Tremblay \& Willms, 2003; Wang, 2001). It is therefore of considerable public importance that further research be conducted to assess the degree to which access to public play spaces differs among neighbourhoods of varying social, economic and environmental characteristics. The purpose of this paper is to examine the spatial distribution of recreational opportunities for children and youth in a mid-sized Canadian city (London, Ontario) in relation to the socioeconomic status of neighbourhoods and estimated local need for publicly provided play spaces.

\section{Physical activity, accessibility and vulnerable children and youth}

Physical activity helps to improve many aspects of children's lives. For instance, increases in physical activity have been correlated with academic achievement, healthy body weight promotion, positive self-esteem and positive attitudes and behaviours (American College of Sports Medicine, 2000; Canadian Paediatric Society 2002; Ritchie et al., 2001). Efforts to increase energy expenditure are clearly necessary, as more than $50 \%$ of youth in Canada and the United States are not physically active enough to achieve health benefits (Craig et al., 2001; Sallis \& Patrick 1994; Sallis et al., 2000).

There are numerous determinants of physical activity levels among children and adolescents. One recent line of research suggests that attributes of the physical environment natural and built features - can influence behaviour and facilitate or deter physical activity. Researchers have found that convenient access to local recreational facilities such as parks, recreation centres and health clubs is associated with higher rates of physical activity (Brownson et al., 2001; Huston et al., 2003; Sallis et al., 1997, 2000). Recent Canadian research by Irwin, Tucker and colleagues revealed that parents' perceptions of neighbourhood safety and proximity of activity facilities were significant barriers to physical activity for preschool-aged children (Irwin et al., 2005; Tucker et al., in press). Humbert and colleagues (2006) also identified proximity and safety as important factors for youth activity. Compared to adults, children and youth have fewer transportation options and are generally more captive (vulnerable) to the 'opportunity structures' in their local environments (Armstrong, 1993; Kytta, 2004; Macintyre \& Ellaway, 2000). Opportunity structures are features of the social and physical environment which may support or hinder people's abilities to choose healthy behaviours (Macintyre et al., 2002).

Studies indicate that adults and children living in socially disadvantaged neighbourhoods of low average income tend to have higher levels of obesity and are more vulnerable to obesity-related health problems (Diez-Roux et al., 1997; Lin et al., 2004; Robert \& Reither, 2004; Storey et al.,2003; Wang, 2001). Several studies have made the link between low socioeconomic status and lower levels of physical activity (Cauley et al., 1991; Giles-Corti \& Donovan, 2002; Gordon-Larsen et al., 2000; Sallis et al., 1996; Yen \& Kaplan, 1998). It has been suggested that youth from low-income households may be less active because low-income neighbourhoods are less likely to contain accessible spaces that support physical activity, such as parks or community centres (Loukaitou-Sideris, 2002; Romero, 2005; Talen, 1997; Talen \& Anselin, 1998). Conversely, research has shown that public parks have higher rates of use in poor, inner-city neighbourhoods compared to those in wealthy suburbs, whose residents are more likely to have access to private recreation spaces 
(Loukaitou-Sideris, 1995). When dealing with economically vulnerable populations, it is important to recognize that 'accessibility' is also dependent on the fees for using a facility, as well as geographic location; therefore, publicly funded, low (or no) cost recreational opportunities are a necessity in socially distressed neighbourhoods with high concentrations of low-income households.

In light of current knowledge on the childhood obesity problem, this paper explores environmental equity with respect to opportunity structures for physical activity in London, Ontario. While environmental equity research is almost always focused on identifying demographic disparities in exposure to 'LULUs' (locally unwanted land uses) such as air pollution and toxic waste (Greenberg \& Cidon, 1997), our concern in this paper is the equitable distribution of health-promoting features in the urban landscape: public recreation spaces. The primary objective is to examine the spatial distribution of publicly funded recreational opportunities for youth in relation to the socioeconomic status of neighbourhoods and the anticipated level of neighbourhood need for publicly provided recreation spaces. Our primary hypothesis is that public recreational facilities are relatively underconcentrated in disadvantaged neighbourhoods with low socioeconomic status.

\section{Methods}

The locations of all publicly funded recreational spaces $(N=537)$ such as swimming pools, wading pools, tennis/basketball courts, soccer fields, baseball diamonds, community centres and arenas in the urbanized areas $\left(\geq 1000\right.$ people $\left./ \mathrm{km}^{2}\right)$ of the city of London, Ontario, Canada (approximately 340,000 inhabitants) were mapped in a geographic information system (ArcGIS 9.1) using data that were provided by the City of London Planning Department (2005) and updated by the researchers through inspection of air photos and exhaustive field surveys. Municipal 'planning districts' were used as the areal unit of measurement in this study as they were designed carefully by city planners and analysts with extensive local knowledge to represent 'natural neighbourhoods' (Ross et al., 2004) and are delineated typically by more meaningful boundaries (e.g. major streets, rivers, railroad tracks) than other commonly used areal units such as census tracts (CT). Furthermore, as the City of London directs many of its planning policies and resources according to these boundaries, our policy recommendations are therefore likely to be more effective if we use equivalent boundaries.

To identify neighbourhood characteristics, all non-rural planning districts $(N=22)$ were characterized by two different indices comprised of socioeconomic and environmental indicators derived from the 2001 Census of Canada at the dissemination area level. The first index, a composite neighbourhood 'social distress index', was created by compiling measures for three of the most commonly used indicators of socioeconomic status: median household income, level of educational attainment (proportion of population over 20 years of age with a high school diploma) and proportion of families headed by lone parents. Following the 'modified quantile approach' recommended by Brewer and Pickle (2002), planning districts were classified into quintiles according to the sum of their rankings for each of the three socioeconomic indicators and attributed an index score ranging from 1 to 5 (least distressed to most distressed). This index is similar to other well-established 'deprivation indices' (e.g. Ley \& Smith 2000), except that the measure does more than distinguish a small number of deprived 'underclass' districts: it identifies neighbourhoods that are distressed across multiple measures and it retains a large amount of variation between neighbourhoods (cf. Gilliland \& Ross, 2005).

To explore further the issue of environmental equity and public recreation facilities, planning districts were also characterized by a 'play space needs index' which incorporates 
three neighbourhood indicators of material, physical and psychological need. The measure dwelling type mix takes into consideration the relative proportions of different types of homes in each district and attributes a needs score according to the amount of private outdoor space typically associated with that particular housing form (e.g. single-detached house $=1$, semi-detached $=2$, row-house (terraced) $=3$, low-rise and mid-rise apartments $=4$, high-rises $=5$ ). Youth density (residents under 16 years of age per square kilometre) takes into consideration the concentration of potential 'users' of neighbourhood facilities. The third measure, household crowding, assumes that increasing numbers of people per household will be associated with an increasing level of need for recreation space away from the home environment.

The combination of these three variables produces a neighbourhood index that is targeted more specifically to the research subject than the more generic social distress index, in that it is explicitly designed to capture the material, physical and psychological needs for the provision of public recreation space in the neighbourhood. The play space needs index score was calculated using the same modified quantile approach as the social distress index.

Neighbourhood opportunity structures for physical activity were measured using two outcome measures derived for each non-rural planning district. Recreation opportunity (RO) density refers to the number of recreational opportunities per square kilometre. We also examined (RO) prevalence, or the number of recreational opportunities per 1000 children and youth (under 16 years), to account for variations in population density throughout the city.

\section{Results}

Research identified a total of 537 publicly funded recreational opportunities in London, including 196 baseball diamonds, 140 playgrounds, 98 soccer/football fields, 43 tennis/basketball courts, 26 wading pools/splashpads, 13 swimming pools, 11 community centres and 10 arenas. The exercise of identifying, geocoding and mapping formal recreation facilities in London reveals that many opportunities for physical activity exist for young people and that every planning district has at least two publicly funded spaces for youth recreation (see Figure 1). Nevertheless, the mapping also reveals that there are some 'recreational deserts' in the city, that is, areas where it would be difficult for a young person to find a formal place to play within walking distance of home. A closer look at the map, for example, reveals that certain areas of the urban core (around the border between Central and East London) and the rural-suburban fringes are recreational deserts.

Although the maps in Figures 1 and 2 do not reveal any strong spatial pattern of social inequity with respect to the provision of public facilities, the data suggest that the most distressed districts (index score $=5$ ) actually have, on average, one-and-a-half times more recreational opportunities per square kilometre than the least distressed districts (RO density $=$ 4.64 and $2.78 \mathrm{RO} / \mathrm{km}^{2}$, respectively). Furthermore, the only two districts that scored in the least distressed quintile for all three indicators - Masonville and Uplands, in the North are also the most poorly provided with public recreational facilities (by density and prevalence). These findings suggest that our primary hypothesis that public recreational facilities are relatively under-concentrated in socially distressed neighbourhoods is false. In actuality, there is a moderate positive relationship between RO density and neighbourhood distress level (Spearman's rho $=0.469, p>0.05$ ). On the other hand, there is little or no correlation between levels of neighbourhood distress and RO prevalence (Spearman's rho $=$ $0.181, p>0.05)$. Figure 3 illustrates that there is no obvious relationship between the number of recreation opportunities per number of youth in a neighbourhood and its level 


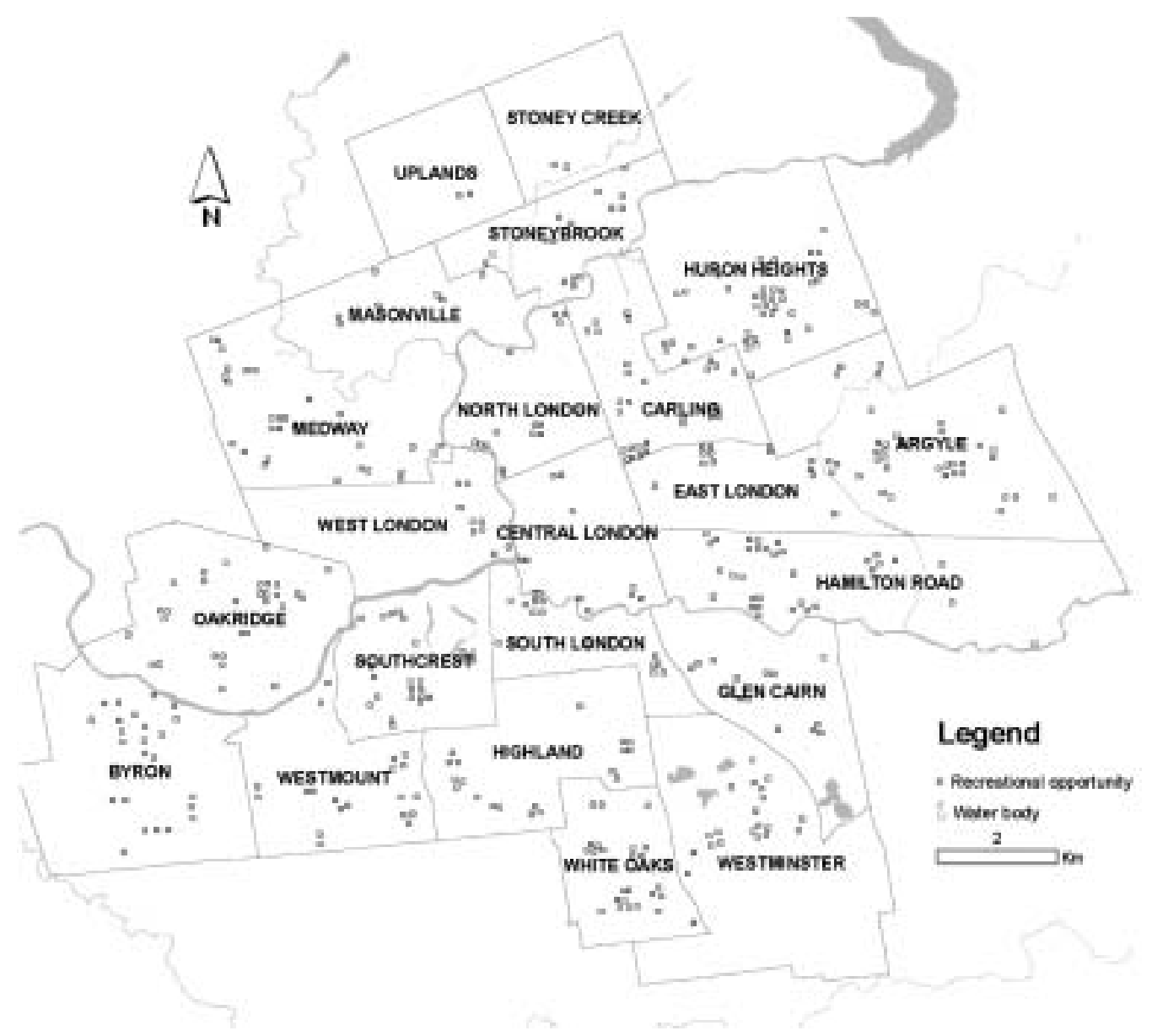

Figure 1. Geographical distribution of selected public recreation opportunities in London, Ontario.

of social distress. In fact, the least distressed districts in London had virtually identical RO prevalence scores as the most distressed districts (19.3 and $19.7 \mathrm{RO} / 1000$ youth, respectively).

An alternative look at the evidence against the backdrop of neighbourhood play space needs index scores suggests that recreational spaces have not necessarily been provided in the areas where they are most needed. Figure 4 identifies prevalence of recreational opportunities per number of youth in each planning district in relation to how the district scored on the play space needs index. On average, the districts estimated to have the greatest need have barely half the number of recreational opportunities per youth as the districts with lowest levels of need (RO prevalence $=15.3$ and $29.1 \mathrm{RO} / 1000$ youth, respectively). For instance, the Glen Cairn district in the Southeast, which is estimated to have the greatest need for recreational opportunities of any district in the city, also has the fewest number of recreational opportunities per youth of any district (10.1 RO/1000 youth); meanwhile, the four districts estimated to have lowest levels of need for public play spaces (lightest shade on Figure 4) in actuality all have RO prevalence levels greater than the London average ( $>21.1 \mathrm{RO} / 1000$ youth). Correlation analysis indicates that there is a strong inverse relationship between RO prevalence and need (Spearman's rho $=-0.606, p<0.01$ ). Despite 

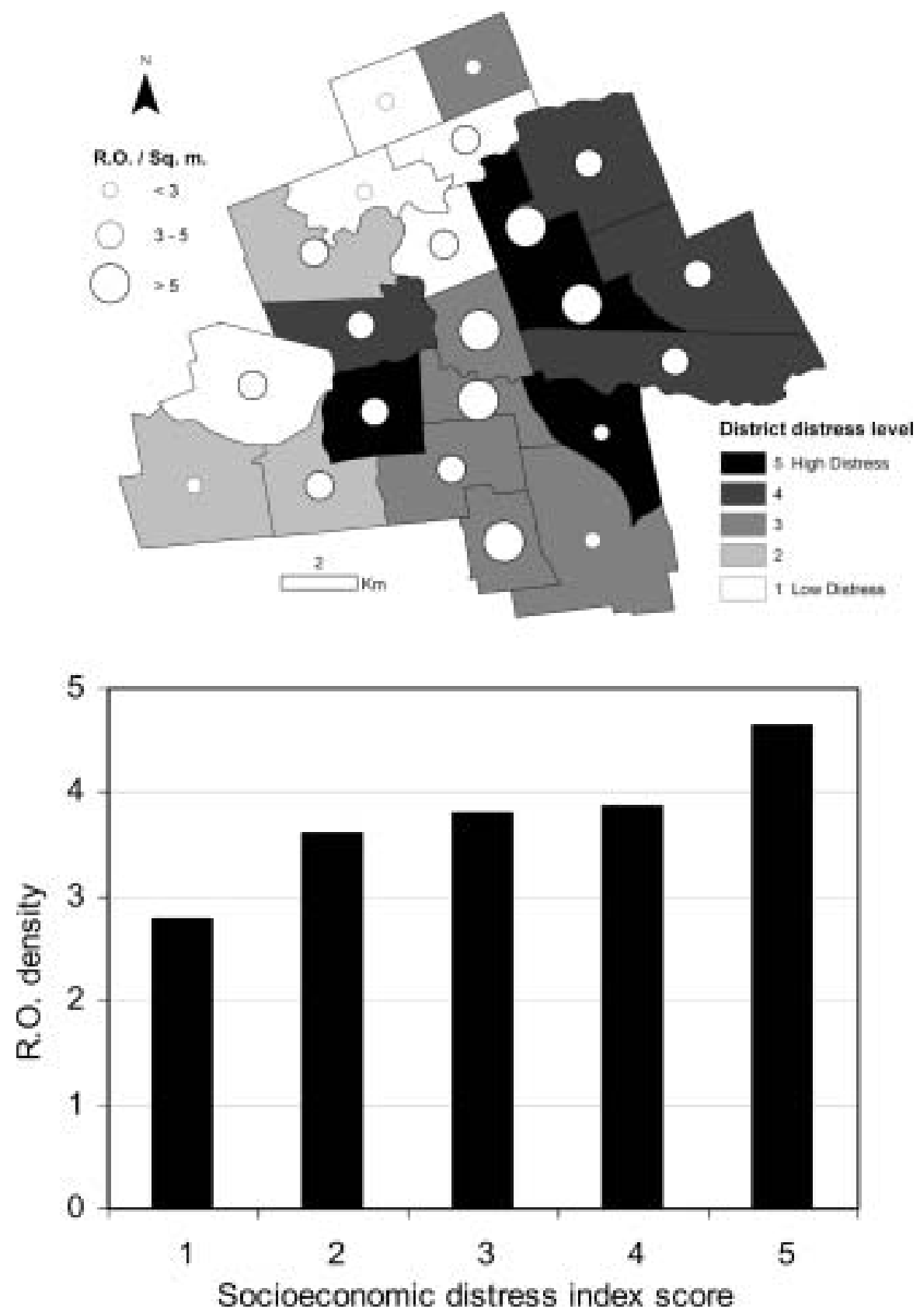

Figure 2. Density of recreational opportunities and neighbourhood socioeconomic distress levels.

the apparent mismatch between opportunities and need, the graph in Figure 5 alternatively suggests that the density of recreation opportunities is, on average, greatest in districts scoring highest on the needs index $\left(4.82 \mathrm{RO} / \mathrm{km}^{2}\right)$. Nevertheless, the map in Figure 5 does not indicate any obvious pattern with respect to neighbourhood needs levels and the density of recreational opportunities. Furthermore, correlation analysis indicates that there is little or no relationship between needs levels and RO density (Spearman's rho $=0.279, p>0.05$ ). 

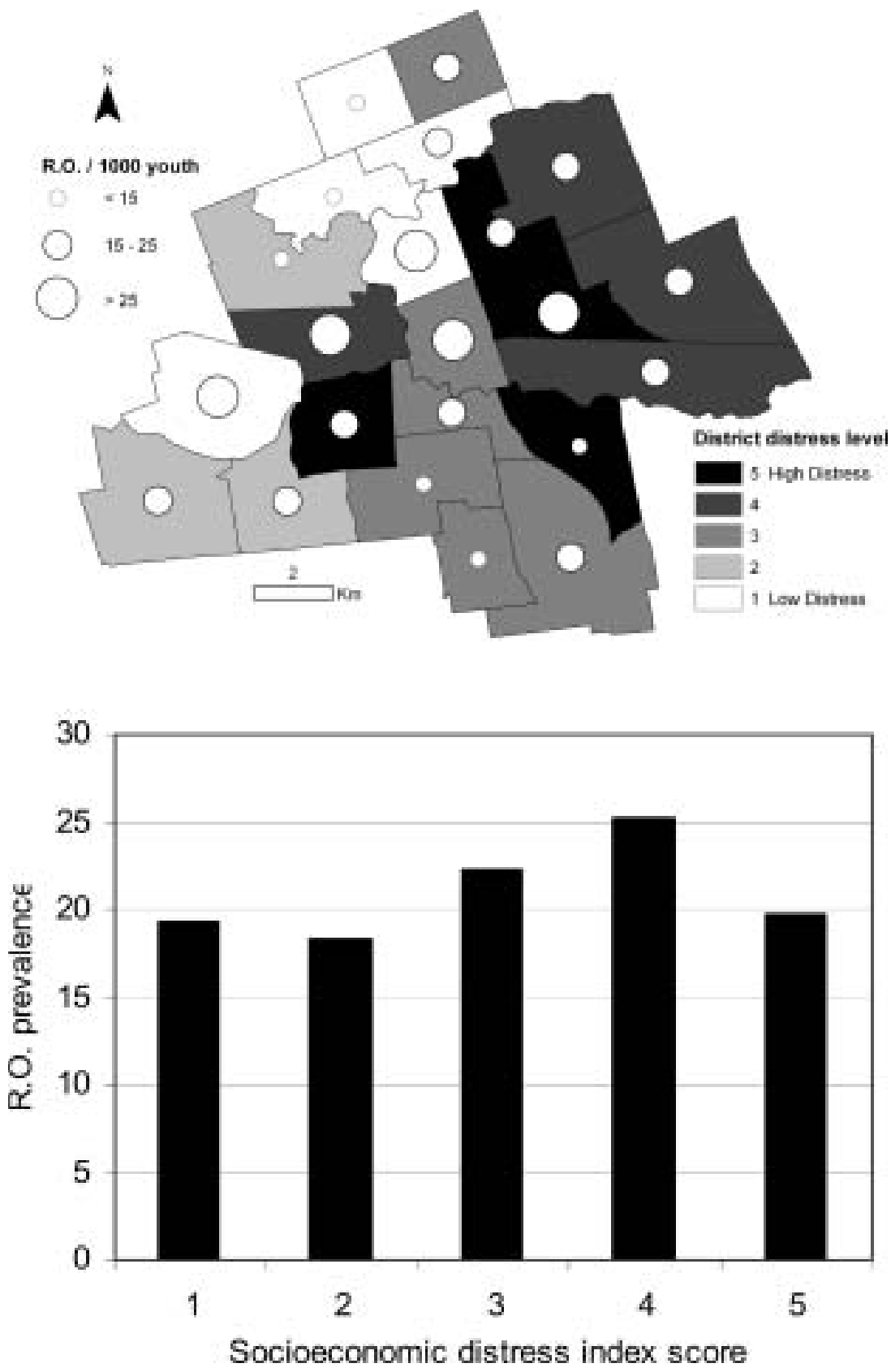

Figure 3. Prevalence of recreational opportunities and neighbourhood socioeconomic distress levels.

\section{Discussion and conclusions}

It has been suggested that young people from disadvantaged backgrounds have a greater need for publicly funded recreation opportunities close to home because they are less likely to have the household resources necessary to access private recreation opportunities (i.e. 'play for pay'), such as organized sporting leagues, private gyms/health clubs or, simply, a 

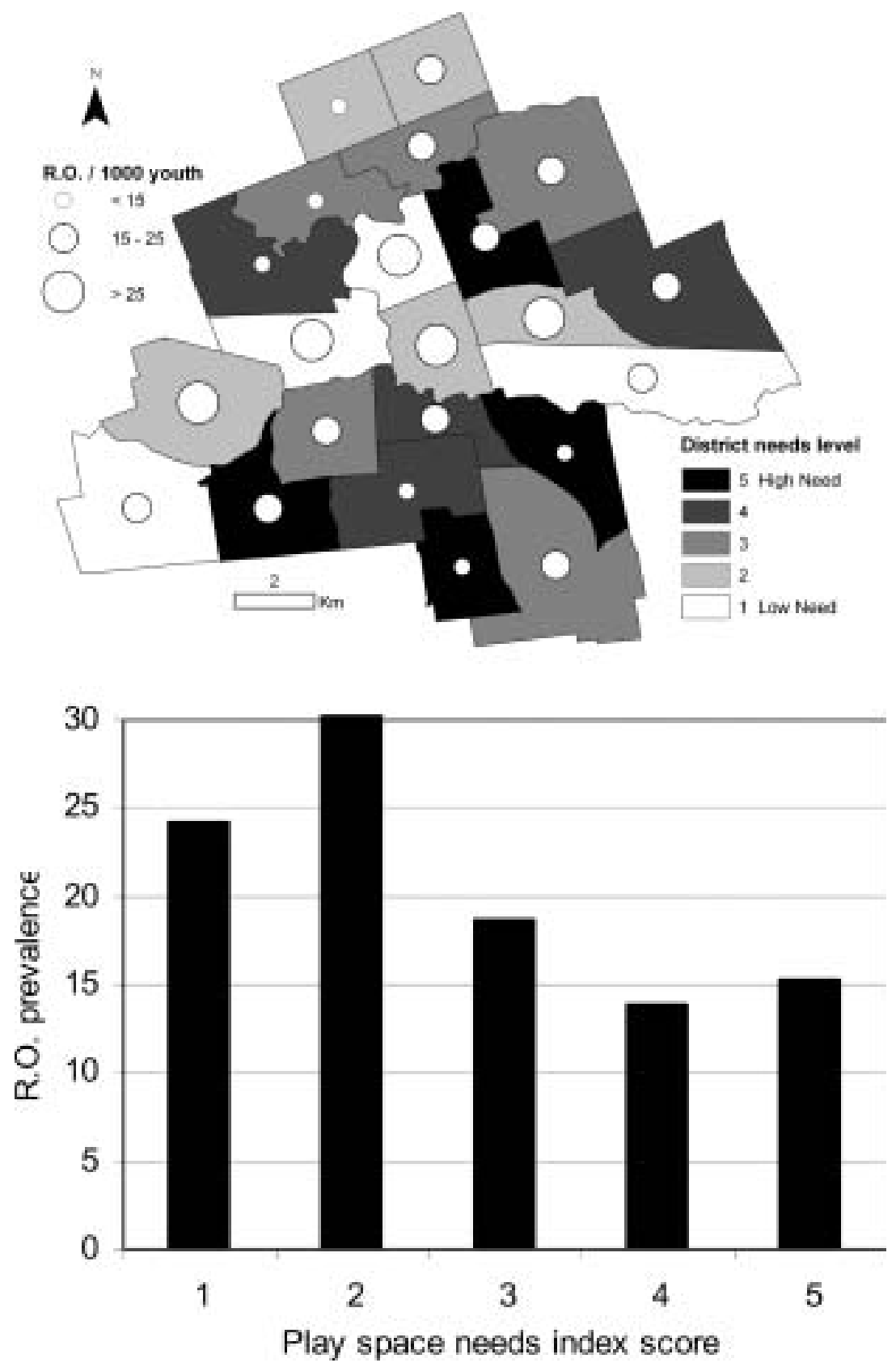

Figure 4. Prevalence of recreational opportunities and neighbourhood need for play space.

large back yard (Romero, 2005). Recent research in Los Angeles by Wolch and colleagues (2005) indicates that residents of low-income neighbourhoods dominated by visible minorities have dramatically lower levels of access to public park resources than other residents (cf. Loukaitou-Sideris, 2002; Talen, 1997). Our expectations drawn from previous (largely US) studies about the lack of environmental equity in relation to neighbourhood recreation spaces were not borne out here: findings for London do not suggest that there is a sociospa- 

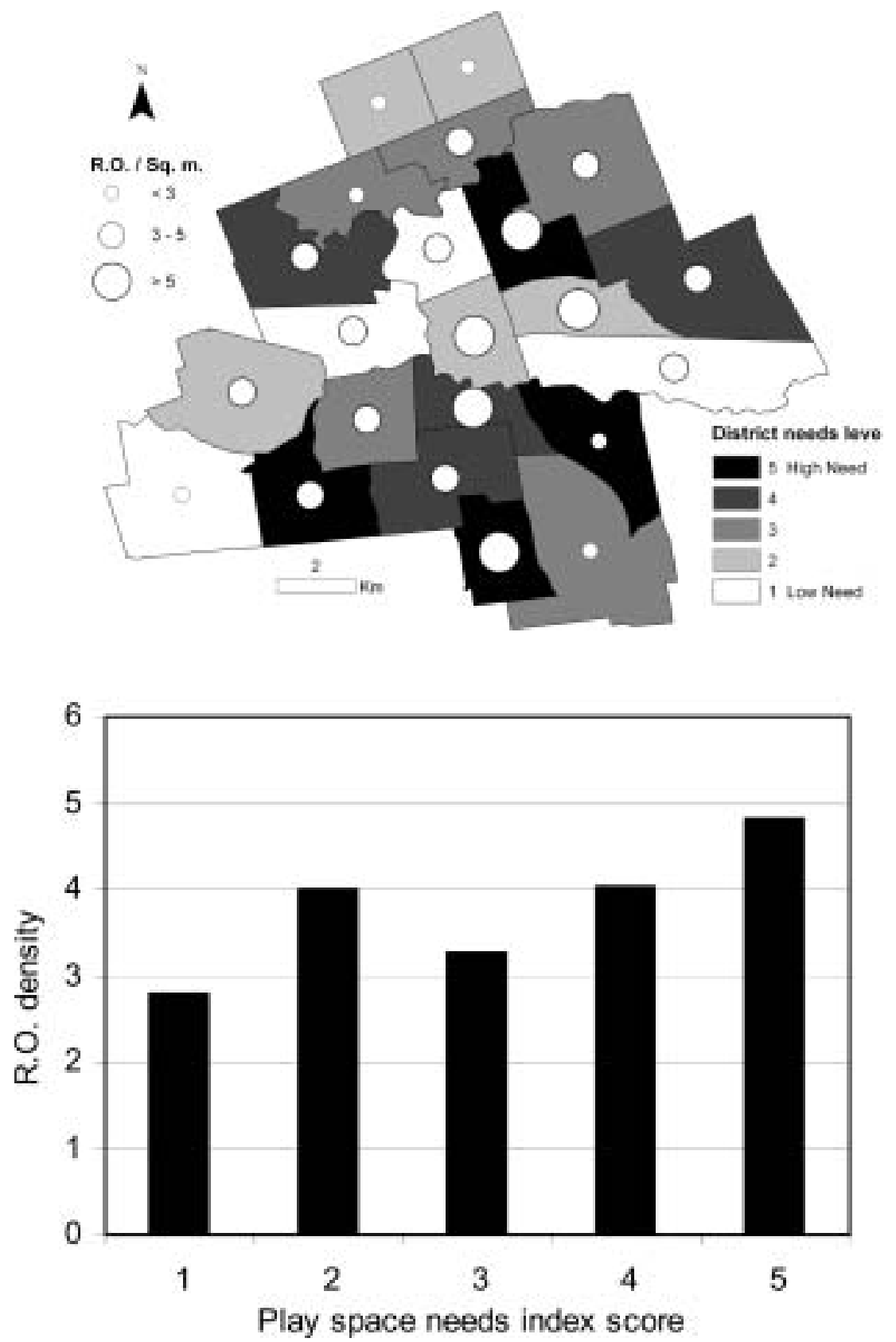

Figure 5. Density of recreational opportunities and neighbourhood need for play space.

tial disparity of recreation opportunities in relation to neighbourhood socioeconomic status. In actuality, the results indicate that the density of recreational opportunities is greatest in the most socially distressed neighbourhoods; however, when the distribution of youth (prevalence) is considered, the relationship no longer appears significant. On the other hand, additional analyses indicate that the prevalence of recreational opportunities is lowest 
in neighbourhoods with the greatest need, even though there is no significant relationship between density of opportunities and need. The substantially different results produced by the two outcome measures (density and prevalence) justify the importance of looking at both measures and highlight the need for future researchers of park equity to standardize, as much as possible, the outcome measures, geographic units and neighbourhood indexes, if appropriate comparisons between cities are to be made.

The findings suggest that other factors besides socioeconomic status or need may be implicated as influencing the distribution of recreational opportunities in the city, such as the era in which the neighbourhood was developed. Before the 1940s, urban development in London occurred piecemeal; small builders erected a few buildings at a time, with little attention given to neighbourhood recreation spaces. In London, as in most North American cities, a large public park (Victoria Park) in the city centre served as the 'lungs' of the city. Following WWII and a nationwide housing shortage, large-scale developers came onto the scene to erect 'master planned' suburban communities complete with elementary and secondary schools, and multiple neighbourhood parks and playing fields for children of the 'baby boom' generation. More recently, over the last two or three decades, large-scale residential subdivisions have continued to appear at the suburban-rural fringe in London, but builders appear to be squeezing in a greater number of lots and leaving less room for formal recreation spaces (on development trends in London, see Dennett, 1999). These changing trends deserve further study than can be given here, but it is likely that they are a response to the changing lifestyles, recreation habits and consumer demands of an ageing population.

The results of the present study indicate clearly that 'recreational deserts' exist within the city of London. Nevertheless, this study has used a rather rudimentary geographic information system (GIS)-based method - the typical 'containment' approach - to measure service provision; a more sensitive measure of service accessibility might suggest alternatively that the distribution of recreation spaces in London is much less (or more) equitable than previously believed. While more sophisticated GIS-based techniques of 'proximity analysis' are available, and have been used in recent environmental equity studies to estimate distances between certain hazards or amenities and various populations (see Mohai \& Saha, 2006; Wilson et al., 2006), we chose strategically to focus on assessing levels of public park provision in relation to the planning districts used by the City of London planning department, in order to increase the likelihood that our study might stimulate positive interventions in the local environment.

Although the primary purpose of this paper was to examine the spatial distribution of publicly provided recreational opportunities for children and youth in relation to neighbourhood characteristics, it must also be acknowledged that simply providing access to recreational opportunities is only a first step in promoting physical activity among young people. Ongoing research using field surveys, interviews with parents and focus groups with elementary school children will investigate various interrelated dimensions of access, quality and use of play spaces throughout the city to further examine potential disparities among neighbourhoods of high and low socioeconomic status and different levels of need. Park quality may vary significantly throughout the city, or within a particular district. The amount and types of amenities (e.g. playground equipment, water fountains, lavatories, landscaping, open space) and disamenities (e.g. litter, graffiti, needles, broken bottles) often associated with city parks may not be distributed equitably throughout London, and this potentially inequitable pattern may influence usage rates, physical activity levels and overall health and well-being of children and youth throughout the city. In a recent qualitative study of 28 parks in Montreal, Coen and Ross (2006) discovered that parks located in neighbourhoods of poor average health status tended to be of lower quality, exhibiting material disadvantages 
such as lack of facilities and concentration of physical incivilities. Further qualitative research involving interviews with parents of young children should be aimed at uncovering parents' perceptions of particular parks, the relative importance of accessibility versus quality and what park elements are most important when making the choice of where to play. Furthermore, focus groups with children and youth could be used to identify what kinds of public recreation spaces are most attractive, most utilized, and therefore most effective for promoting healthy behaviours among vulnerable populations of different age levels and cultural backgrounds. Such research, tied to community population projections, should help city planners decide how to best target increasingly scarce public resources.

Childhood obesity is a critical public health issue in a number of countries, including Canada. It is of considerable importance that the sociospatial dimensions of public recreation opportunities are uncovered in different communities as children and youth in disadvantaged areas are at a greater risk of becoming obese and are more vulnerable to obesity-related health problems. The results of this ongoing study should be useful to those interested in, and capable of, promoting healthy environments through planning, promotion and education. Given the scarcity of large parcels of open space in older (already developed) areas of the city, it is recommended that in order to rectify current inequities, city planners adopt innovative strategies for providing new recreation spaces in older neighbourhoods, such as the acquisition and redevelopment of underutilized school yards, vacant lots, 'brownfield' sites (i.e. former industrial land) and 'greyfield' sites (e.g. former commercial plazas). Furthermore, it is recommended that future investments of increasingly scarce resources be aimed at creating multi-purpose recreation spaces: underutilized tennis courts offer ideal surfaces for sports that are currently fashionable among Canadian youth, such as basketball, ball hockey and skateboarding; similarly, grassy fields dedicated to North American sports such as baseball and football are adapted easily to accommodate sports such as soccer, rugby and cricket, which are popular among youth of different ethno-cultural communities in Canada. By ensuring that new publicly funded recreation opportunities are targeted effectively at neighbourhoods with the greatest need, it is perhaps possible to increase physical activity levels among vulnerable children and youth and ultimately to help to fight the obesity epidemic in developed nations.

\section{References}

American College of Sports Medicine (2000). ACSM's guidelines for exercise testing and prescription, 6th edn. Philadelphia PA: Lippincott.

American Obesity Association (2002). AOA fact sheets - obesity inyouth. Available at: http://www.obesity.org/ subs/fastfacts/obesity_youth.shtml (accessed 23 March 2006).

Armstrong, N. (1993). Independent mobility and children's physical development. In M. Hillman (Ed.), Children, transport and the quality of life. pp. 35-43. London: Policy Studies Institute.

Brewer, C.A., \& Pickle, L. (2002). Comparison of methods for classifying epidemiological data on choropleth maps in series. Annals of the Association of American Geographers, 92, 662-681.

Brownson, R.C., Baker, E.A., Housemann, R.A., Brennan, L.K., \& Bacak, S. (2001). Environmental and policy determinants of physical activity in the United States. American fournal of Public Health, 91, 1995-2003.

Cauley, J., Donfield, S., Laporte, R., \& Warhaftig, N. (1998). Physical activity by socioeconomic status in two population based cohorts. Medicine and Science in Sports and Exercise, 23, 343-351.

Canadian Paediatric Society (CPS) (2002). Healthy active living for children and youth. Pediatrics and Child Health, 7, 339-345.

City of London (2005). Mapping data distribution. London, Ontario: Corporation of the City of London.

Coen, S.E., \& Ross, N.A. (2006). Exploring the material basis for health: characteristics of parks in Montreal neighborhoods with contrasting health outcomes. Health $\&$ Place, 12, 361-371.

Craig, C.L., Cameron, C., Russell, S.J., \& Beaulieu, A. (2001). Increasing physical activity: supporting children's participation. Ottawa, ON: Canadian Fitness and Lifestyle Research Institute.

Dennett, C. (1999). Bricks and mortar: the Sifton story. London, ON: Sifton Properties Limited. 
Diez-Roux, A.V., Nieto, F.J., Muntaner, C., Tyroler, H.A., Comstock, G.W., Shahar, E., et al. (1997). Neighbourhood environments and coronary heart disease: a multilevel analysis. American fournal of Epidemiology, 146, 48-63.

Frank, L.D., Schmid, T.L., Sallis, J.F., Chapman, J., \& Saelens, B.E. (2005). Linking objectively measured physical activity with objectively measured urban form: findings from SMARTRAQ. American fournal of Preventive Medicine, 28, 117-125.

Giles-Corti, B., \& Donovan, R.J. (2002). Socioeconomic status differences in recreational physical activity levels and real and perceived access to a supportive physical environment. Preventative Medicine, 35, 610-611.

Gilliland, J., \& Ross, N. (2005) Opportunities for video lottery gambling: an environmental analysis. Canadian Fournal of Public Health, 96, 55-59.

Gordon-Larsen, P., McMurray, R.G., \& Popkin, B.M. (2000). Determinants of adolescent physical activity and inactivity patterns. Pediatrics, 105, 1-8.

Greenberg, M., \& Cidon, M. (1997). Broadening the definition of environmental equity: a framework for states and local governments. Population Research and Policy Review, 16, 397-413.

Humbert, M.L., Chad, K.E., Spink, K.S., Muhajarine, N., Anderson, D., Bruner, M.W., et al. (2006). Factors that influence physical activity participation among high- and low-SES youth. Qualitative Health Research, 16, 467-483.

Huston, S.L., Evenson, K.R., Bors, P., \& Gizlice, Z. (2003). Neighbourhood environment, access to places for activity, and leisure-time physical activity in a diverse North Carolina population. American fournal of Health Promotion, 18, 58-69.

Irwin, J.D., He, M., Sangster Bouck, L.M., Tucker, P., \& Pollett, G.L. (2005). Preschoolers' physical activity behaviours; parents' perspectives. Canadian fournal of Public Health, 96, 299-303.

Kytta, M. (2004). The extent of children's independent mobility and the number of actualized affordances as criteria for child-friendly environments. Fournal of Environmental Psychology, 24, 179-198.

Ley, D., \& Smith, H. (2000). Relations between deprivation and immigrant groups in large Canadian cities. Urban Studies, 37, 376-362.

Lin, B.H., Huang, C.L., \& French, S.A. (2004). Factors associated with women's and children's body mass indices by income status. International fournal of Obesity Related Metabolic Disorders, 28, 536-542.

Loukaitou-Sideris, A. (2002). Children in Los Angeles parks: A study of equity, quality, and children's satisfaction with neighbourhood parks. Town Planning Review, 73, 467-488.

Loukaitou-Sideris, A. (1995). Urban form and social context: cultural differentiation in the uses of urban parks. Fournal of Planning Education and Research, 14, 89-102.

Macintyre, S., \& Ellway, A. (2000). Ecological approaches: Rediscovering the role of the physical and social environment. In L. F. Berkman \& I. Kawachi (Eds), Social epidemiology. pp. 332-348. New York: Oxford University Press.

Macintyre, S., Ellaway, A., \& Cummins, S. (2002). Place effects on health: how can we conceptualize, operationalise, and measure them? Social Science and Medicine, 55, 125-139.

Mohai, P., \& Saha, R. (2006). Reassessing racial and socioeconomic disparities in environmental justice research. Demography, 43, 383-399.

National Statistics (2004). Diet and nutrition - proportion of overweight children up. Available at: http:// www.statistics.gov.uk/ (accessed 23 March 2006).

Ritchie, L.D., Ivey, S., Masch, M., Woodward, G., Ikeda, J., \& Crawford, P. (2001). Pediatric overweight: a review of the literature. Berkeley, CA: The Centre for Weight and Health, University of California.

Robert, S.A., \& Reither, E.N. (2004). A multilevel analysis of race, community disadvantage, and body mass index among adults in the US. Social Science and Medicine, 59, 2421-2434.

Romero, A. (2005). Low-income neighbourhood barriers and resources for adolescents' physical activity. Fournal of Adolescent Health, 36, 253-259.

Ross, N.A., Tremblay, S.S., \& Graham, K. (2004). Neighbourhood influences on health in Montréal, Canada. Social Science and Medicine, 59, 1485-1494.

Sallis, J.F., McKenzie, T., Elder, J.P., Broyles, S.L., \& Nader, P.R. (1997). Factors parents use in selecting play spaces for young children. Archives of Pediatrics and Adolescent Medicine, 151, 414-417.

Sallis, J.F., \& Patrick, K. (1994). Physical activity guidelines for adolescents: Consensus statement. Pediatric Exercise Science, 6, 302-314.

Sallis, J.F., Prochaska, J.J., \& Taylor, W.C. (2000). A review of correlates of physical activity of children and adolescents. Medicine and Science in Sports and Exercise, 32, 963-975.

Sallis, J.F., Zakarian, J.M., Hovell, M.F., \& Hofstetter, R. (1996). Ethnic, socioeconomic, and sex differences in physical activity among adolescents. Fournal of Clinical Epidemiology, 49, 125-134.

Saelens, B., Sallis, J.F., Black, J.B., \& Chen, D. (2003). Neighbourhood-based differences in physical activity: An environment scale evaluation. American fournal of Public Health, 93, 1552-1563.

Storey, M.L., Forshee, R.A., Weaver, A.R., \& Sansalone, W.R. (2003). Demographics and lifestyle factors associated with body mass index among children and adolescents. International fournal of Food, Science, and Nutrition, 54, 491-503. 
Talen, E. (1997). The social equity of urban service distribution: An exploration of park access in Pueblo, Colorado, and Macon Georgia. Urban Geography, 19, 521-541.

Talen, E., \& Anselin, L. (1998). Assessing spatial equity: an evaluation of measures of accessibility to public playgrounds. Environment and Planning, 30, 595-613.

Tremblay, M.S., Katzmarzyk, P.T., \& Willms, J.D. (2002). Temporal trends in overweight and obesity in Canada, 1981-1996. International fournal of Obesity and Related Metabolic Disorders, 26, 538-543.

Tremblay, M.S., \& Willms, J.D. (2000). Secular trends in the body mass index of Canadian children. Canadian Medical Association fournal, 163, 1429-1433.

Tremblay, M.S., \& Willms, J.D. (2003). Is the Canadian childhood obesity epidemic related to physical inactivity? International fournal of Obesity and Related Metabolic Disorders, 27, 1100-1105.

Tucker, P., Irwin, J.D., Sangster Bouck, L.M., He, M., \& Pollett, G.L. (2006). Preventing pediatric obesity; recommendations from a community-based qualitative investigation. Obesity Reviews, 7, 251-260.

Yen, I., \& Kaplan, G. (1998). Poverty area of residence and changes in physical activity level: Evidence from Almeda County Study. American fournal of Public Health, 88, 1709-1712.

Wang, Y. (2001). Cross-national comparison of childhood obesity: The epidemic and the relationship between obesity and socioeconomic status. International fournal of Epidemiology, 30, 1129-1136.

Wilson, D.A., Gilliland, J., Ross, N., Derevensky, J., \& Gupta, R. (2006). Video lottery terminal access and gambling among high school students in Montréal. Canadian fournal of Public Health, 97, 202-206.

Wolch, J., Wilson, J.P., \& Fehrenbach, J. (2005). Parks and park funding in Los Angeles: An equity-mapping analysis. Urban Geography, 26, 4-35. 